\title{
Fact sheet-How does quality of care relate to a rights-based approach to family planning programs?
}

Jan Kumar

Follow this and additional works at: https://knowledgecommons.popcouncil.org/departments_sbsr-rh

Part of the Demography, Population, and Ecology Commons, Family, Life Course, and Society Commons, International Public Health Commons, Maternal and Child Health Commons, and the Women's Health Commons How does access to this work benefit you? Let us know!

\section{Recommended Citation}

"Fact sheet-How does quality of care relate to a rights-based approach to family planning programs?" Washington, DC: Population Council, 2016. 


\section{HOW DOES QUALITY OF CARE RELATE TO A RIGHTS-BASED APPROACH TO FAMILY PLANNING PROGRAMS?}

\section{BACKGROUND}

Quality of care has been a focus of health care for nearly a century, and of family planning (FP) programs specifically since the early 1990s. After the initial focus on establishing services and generating demand early in international FP, assuring quality became a legitimate concern, resulting in a proliferation of tools and research on quality of care's impact on client behaviors and health outcomes. Meanwhile, protecting clients with a rights-based approach (RBA) became more central to health initiatives. Because policymakers are challenged by these numerous, overlapping constructs, with uncertainty about which to adopt, there is a need for common understanding of each construct and its contribution to FP.

\section{DISCUSSION}

Several definitions of quality in health care are widely accepted. Donabedian's framework established both clinical and human aspects and introduced the concepts of good client-provider relations, continuity of care, and equitable access. Years later, the UN Committee on Economic, Social and Cultural Rights issued General Comment 14 on Article 12 of the Right to Health, articulating four essential elements for individuals' "highest attainable standard of health": availability, accessibility, acceptability, and good quality. WHO defines quality care in terms of health systems and their outcomes. URC's Quality Assurance Project identifies dimensions of quality as bases for its improvement and assurance.

In 1990 Judith Bruce began defining FP quality of care with her framework of six essential elements: method choice; information; technical competence; interpersonal relations; follow up; and appropriate constellation of services. Huezo and Diaz's FPspecific quality of care framework ties quality to

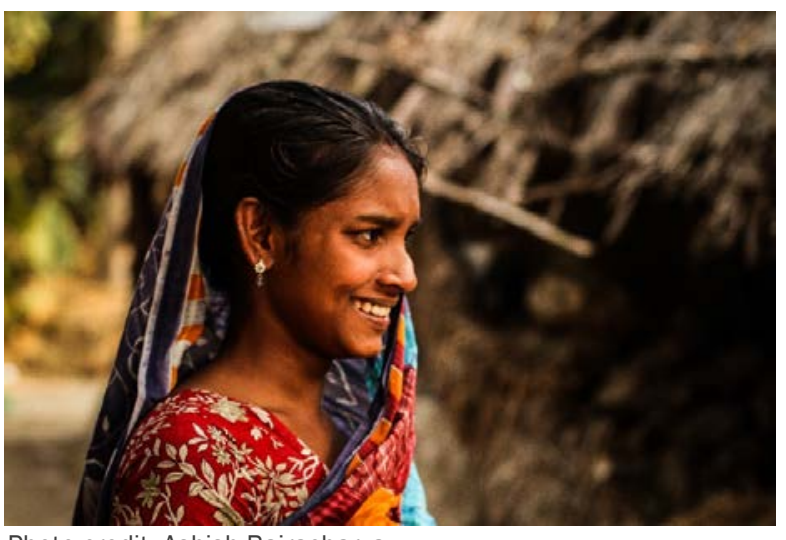

Photo credit: Ashish Bajracharya

clients' rights and what service providers need to fulfill their responsibility for protecting and guaranteeing clients' rights. Many organizations, projects, and initiatives have developed their own service delivery and program frameworks to distinguish their approaches and guide their work, including USAID's Maximizing Access and Quality Initiative begun in 1993, WHO's 2007 health system strengthening framework, Population Council's Situation Analysis, EngenderHealth's SEED Programming Model and Fundamentals of Care, MSI's Quality of Care at the Centre, and IPPF/WHR's efforts to integrate gender into existing quality improvement programs.

Numerous frameworks and guidance documents also explain the rights-based approach, all of which assert the centrality of individuals' dignity and their entitlements, freedoms or rights by virtue of their humanity. Embedding a rights-based approach in FP builds upon what all programs do to improve access to quality services, adding the dimensions of participation, agency, equity-with special attention to marginalized and vulnerable groups-and accountability. Quality is a right, but goes beyond quality of care, by including individuals' active empowerment and engagement to exercise self- 
determination for health and fertility. Several key rightsbased frameworks for development and health in general and FP programs include CARE's rights-based approach to programming; UN's human rights approach, defined by its goal, process, and outcomes; WHO's rights-based approach, with human rights systematically and clearly integrated within contraceptive information and services; UNFPA and WHO technical guidance for operationalizing a human rights-based approach to contraceptive services; FP2020's Rights and Empowerment Working Group's elaboration of 10 rights principles for realizing rightsbased approach for FP programs; and with support from the Gates Foundation, Hardee et al. developed the Voluntary, Rights-based FP Conceptual Framework, an ideal, holistic, rights-based FP program, in all its complexity.

\section{CONCLUSIONS}

Improving and assuring quality of care is a legal, ethical, and practical imperative. Moreover, quality in FP service delivery is instrumental in achieving other desired outcomes that benefit women, children, and programs. However, there is still some variance in how quality in FP is defined across organizations, which hinders priority-setting and consistent monitoring and measurement. Furthermore, the line between quality of care and RBA, which are overlapping but not interchangeable constructs, has become blurred. When looking at the elements of quality in the varied constructs discussed, it is clear is that the Bruce framework and the UN's Comment 14 of Article 12 form the foundation of most operational definitions.

The element of interpersonal relations would be enhanced by ensuring providers know, respect, protect, and fulfill clients' human rights, provide equitable care to all, and do not discriminate. Framing quality of care within human rights, will increase clarity and maintain focus on critical service delivery elements.

If donors embrace, fund, and hold governments accountable to the fullness of RBA for FP with an explicit focus on assuring quality, and if governments and NGOs embed rights principles within FP program planning, implementation, and monitoring, and assuring access without discrimination, in addition to full, free, informed choice for all, they can transform the paths towards their FP2020 goals.

This brief is based on the Working Paper 1 prepared by Jan Kumar for the Measuring and Monitoring Quality of Services and Quality of Care project funded by a grant from the David and Lucile Packard Foundation to the Population Council. We gratefully acknowledge the support and encouragement of the Foundation to continue research on the current state of quality of care.

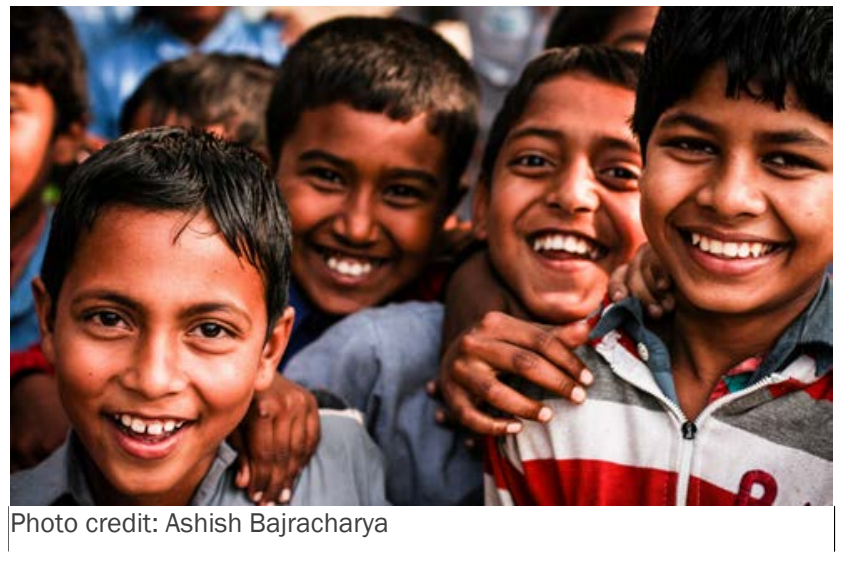

\section{REFERENCES}

1. Assessing Client Profile and Evaluating Client Satisfaction Through Exit Interviews: Guidelines. Marie Stopes International. London.

2. Bruce, J. Fundamental Elements of the Quality of Care: A Simple Framework. Studies in FP 21(2): 61-91.

3. CARE. 2001. Incorporation of a Rights-Based Approach into CARE's Program Cycle: A Discussion Paper for CARE's Program Staff.

4. Creel, L., J. Sass, N. Yinger. 2002. Overview of Quality of Care in $\mathrm{RH}$ : Definitions and Measurements of Quality. Population Council and Population Reference Bureau. New Perspectives on Quality of Care 1.

5. Donabedian, A. Evaluating the Quality of Medical Care. Milbank Memorial Fund Quarterly 44(3:2): 166-203.

6. EngenderHealth. 2011. SEED assessment guide for FP programming. New York.

7. Family Planning 2020: Rights and Empowerment Principles for FP 2014.

8. Hardee, K. Human Rights and Quality of Care. Presentation at Measuring and Monitoring Quality of Care Meeting, 16 Dec 2014.

9. Horstman, R. et al. 2002. Monitoring and Evaluation of Sexual and Reproductive Health Interventions: Manual for EC/UNFPA Initiative for RH in Asia. Netherlands Interdisciplinary Demographic Institute and London School of Hygiene and Tropical Medicine.

10. Huezo, C., S. Diaz. Quality of Care in FP: Clients' Rights and Providers' Needs. Advances in Contraception 9 (2): 129-139.

11. Massoud, R., K. Askov, J. Reinke, L.M. Franco, T. Bornstein, E. Knebel, C. MacAulay. 2001. A Modern Paradigm for Improving Healthcare Quality. QA Monograph Series 1(1). Bethesda, MD: Published for USAID by the Quality Assurance Project.

12. Miller, K., R. Miller, I. Askew et al. 1998. Clinic-based FP and RH Services in Africa: Findings from Situation Analysis Studies. Population Council.

13. UN Committee on Economic, Social and Cultural Rights, General Comment 14. 2000. Article 12 of the Int'I Covenant on Economic, Social and Cultural Rights. Report on 22nd, 23rd, 24th Sessions, Economic and Social Council Official Records, 2001, Supplement 2.

14. UNFPA and WHO. Ensuring Human Rights within Contraceptive Service Delivery: Implementation Guide. 2015.

15. WHO and Office of UN High Commissioner of Human Rights. A Human Rights-based Approach to Health.

16. WHO. 2006. Quality of Care: A Process for Making Strategic Choices in Health Systems.

17. WHO. 2014. Ensuring human rights in the provision of contraceptive information and services: Guidance and Recommendations 